\title{
Performance of Broiler Chicken Fed Sub-Optimal Energy Diets Supplemented With Enzymes and Prebiotics Alone or in Combination
}

\author{
J. Narasimha ${ }^{1}$, D. Nagalakshmi ${ }^{2}$ and M. Venkateswerlu ${ }^{3}$ \\ ${ }^{1,2,3}$ Department of Animal Nutrition, College of Veterinary Science, Rajendranagar, Sri Venkateswara \\ Veterinary University, Hyderabad, Andhra Pradesh, India-500030.
}

\begin{abstract}
An experiment was conducted to study the effect of supplementing Non-starch Polysaccharide enzymes and prebiotics alone or in combination to sub-optimal energy corn soybeanbased broiler diets on performance. 150 day old broiler chicks were randomly distributed in to five experimental groups, six replicates per group and five birds per replicate. A standard diet (SD) and a basal diet (BD) (225 kcal/kg ME less) was formulated for prestarter, starter and finisher periods. Supplementing BD with Non-starch Polysaccharide enzymes with or without prebiotics had no effect on total body weight gain and feed intake. FCR improved with addition of NSP enzymes alone or in combination with prebiotics. The retention of $O M, C P$ and GE was significantly $(P<0.05)$ improved with addition of NSP enzymes along with prebiotics. NSP enzymes alone and or in combination with prebiotics to $B D$ reduced $(P<0.05)$ intestinal $p H$, viscosity, cost of feeding and cost of production per kg live weight gain compared to $B D$ and $S D$.
\end{abstract}

Key words:Non-starch Polysaccharide enzymes, prebiotics, weight gain, FCR, viscosity.

\section{Introduction}

Cereals and vegetable protein sources form the major ingredients in poultry rations. These ingredients contain between 10-75\% of non-starch polysaccharides (NSP) [1]. The first phase was the use of enzymes to enhance nutrient digestibility, focusing primarily on minimizing the anti-nutritive effects of NSP, such as arabinoxylans and $\beta$-glucans from broiler diets based on wheat, rye, barley or triticale which increase the viscosity of digesta. In recent years, soybean meal (SBM) is being used as sole protein source which contains about 29\% NSP [2]. Similarly, other major ingredients used in broiler and layer diets i.e., maize and rice bran contains 9 and 25\% NSP, respectively [2] half of which is cellulose [3]. The beneficial effect of the NSP degrading enzymes is primarily the reduction in the viscosity in GIT and secondarily the release of sugars. Viscosity reduction is due to breakdown of the NSP into smaller polymers thus preventing them from forming viscous net works. Release of sugars due to exogenous enzymes is because of two reasons, firstly breakdown of NSP leads to release of their respective monosaccharides and secondly the breakdown of NSP releases the starch within the endosperm which gets exposed to the endogenous amylase and gets digested and hence, results in release of more glucose [4].

Studies reporting the use of prebiotics (FOS, MOS) in poultry diets have indicated improvements in weight gain and feed efficiency, reduction in mortality and reduction in intestinal colonization by salmonella. [5]reported that feeding lacto sucrose to broilers increased numbers of Bifidobactiria, decreased concentrations of putrefactive products (phenol and p-cresol) and ammonia and increased the concentration of volatile fatty acids in broiler feces. Thus oligosaccharides may potentially be useful in reducing ammonia and other environmental odours emanating from poultry production facilities. Numerous reports indicated beneficial effects of microbial phytase[6], prebiotics and probiotics on the performance of chicken [7]. The mode of action of these feed additives is sometimes complementary and synergetic [8]. Therefore, fortification of chicken diet with combination of these feed additives may further improve the nutrient utilization and performance of bird. However, there are fewer reports highlighting the synergetic/complementary effect of these feed additives on performance of broilers and is an area that needs further attention. In view of the above, present study was aimed to evaluate the effect of feeding NSP degrading enzymes either alone or along with prebiotics in broilers fed corn soybean based sub-optimal energy diets.

\subsection{Experimental Design and Sample Collection}

\section{Materials and Methods}

One hundred and fifty (150) day old Cobb commercial broiler chicks were weighed, wing banded and randomly distributed in to five experimental groups, six replicates per group and five birds per replicate. The NSP enzymes combination (xylanase $7500 \mathrm{IU} / \mathrm{kg}$, cellulase $100 \mathrm{IU} / \mathrm{kg}$ and $\beta$ - D- glucanase $100 \mathrm{IU} / \mathrm{kg}$ ) and with 
prebiotic (MOS) $(0.5 \mathrm{~g} / \mathrm{kg})$ was tested at sub optimal energy concentration $(225 \mathrm{kcal} / \mathrm{kg})$ less MEthan standard diet [9]. The details of experimental diets and ingredient composition are given in Table 1,2 and 3. All replicate groups of chicks were offered the respective diets ad libitum for a period of 42 days. Weekly body weights and feed intake were recorded. At the end of experiment, a metabolic trial of 4 day duration was conducted to determine the nutrient utilization and balance of nutrients. The samples of each feed, feed residue and feces pooled during 4 days period were ground and analyzed for proximate principles as per the method of [10]. After metabolic trial, 30 birds (of 6 birds from each diet by selecting one at random from each replicate) were slaughtered to assess the carcass characteristics.

\subsection{Gut health}

To study the effect of various dietary energy concentrations, supplementary effect of NSP enzymes with or without prebiotic on gut health, the digesta was collected from distal portion of small intestine during slaughter. Approximately two $\mathrm{g}$ of digesta was taken in sterile eppendorf tubes for enumeration of Escherichia coli. Another $2 \mathrm{~g}$ of digesta was collected and centrifuged at $5000 \mathrm{rpm}$ for 10 minutes at $20^{\circ} \mathrm{c}$. An aliquot of supernatant $(0.5$ to $1 \mathrm{ml})$ was collected and stored in capped vials for viscosity determination. The digesta collected in centrifuge tubes was utilized for measuring the $\mathrm{pH}$.

\subsection{Histology of Intestines}

Representative pieces of deodenum of intestine were collected in $10 \%$ formal saline and preserved for histological studies. After proper fixation the intestine tissue was trimmed and subjected to over night washing, dehydration in various percentages of alcohol, cleaning in xylol, embedding in paraffin wax for preparation of blocks [11]. The paraffin blocks were cut in to $5 \mu$ thick sections and stained with routine $\mathrm{H}$ and $\mathrm{E}$ stain [12] and used for microscopic examination.

\subsection{Statistical Analysis}

The data were subjected to appropriate statistical analysis using Statistical Package for Social Sciences (SPSS) $16^{\text {th }}$ version and comparison of means was tested using Duncan's multiple range tests [13].

\section{Results}

\subsection{Nutrient composition of experimental ration} TABLE 4.

Nutrient composition (\% Dry matter basis) of broiler finisher standard and basal diets is presented in

\section{2 performance studies}

The body weight gain in broiler chicks fed basal diet (BD) supplemented with NSP enzymes and/or prebiotics is presented in TABLE5. No significant difference was observed among broiler chicks fed standard diet, BD, BD supplemented with NSP enzymes and prebiotics for starter phase and total period (0-6 weeks). Supplementation of NSP enzymes and prebiotics alone or in combination to BD reduced the feed intake but was higher than the chicks fed standard diet. No significant effect of NSP enzymes and prebiotics supplementation was observed on feed intake. Supplementation of NSP enzymes in combination with prebiotics significantly $(\mathrm{P}<0.05)$ improved FCR during starter and overall period.

\subsection{Nutrient retention}

A metabolic trial of 4 day duration was conducted on 100 birds and data obtained on utilization of nutrients is presented in TABLE6.The utilization of DM, CF, EE, NFE and phosphorus by chicks fed SD, BD and BD supplemented with NSP enzymes and prebiotics were comparable. Supplementation of NSP enzymes, prebiotics and combination of both to $\mathrm{BD}$ significantly $(\mathrm{P}<0.01)$ increased the $\mathrm{OM}$ andCP retention.Supplementation of NSP enzymes and prebiotics in combination increased CP retention (58.69\%) in comparison to $\mathrm{BD}$ and was comparable to $\mathrm{SD}$ group (62.69\%). The $\mathrm{CF}$ and $\mathrm{EE}$ retentions were comparable among SD (32.10 and 76.81\%), BD (29.06 and 71.29\%) BD supplemented with NSP enzymes (32.18 and $74.56 \%$ ) or prebiotics alone (33.42 and 73.33\%) and combination of NSP enzymes and prebiotics (34.37 and $73.51 \%$ ), respectively.Supplementation of BD with NSP enzyme alone and combination with prebiotics improved GE retention. The phosphorus retention was comparable among SD, BD and BD supplemented with NSP enzymes alone or in combination with prebiotics. No influence of supplementing prebiotics either alone or in combination with NSP enzymes was observed on tibia ash.

\section{4 Carcass characteristics}

The slaughter attributes in terms of dressing yield, breast yield, abdominal fat and visceral organs viz., liver, heart and gizzard is presented in TABLE 5.No significant effect was observed among broilers fed standard diet, 
BD, BD supplemented with NSP enzymes, prebiotics alone or in combination on dressing yield.Supplementation of prebiotics alone or in combination with NSP enzymes increased the breast yield $(\mathrm{P}<0.004)$ compared to SD.Dietary variation in addition of NSP enzymes or prebiotics had no effect on abdominal fat. No significant effect of supplementation of BD with NSP enzymes, prebiotics alone or in combination was observed on visceral organs viz., liver, heart and gizzard.

\subsection{Gut Conditions}

No significant $(\mathrm{P}<0.05)$ effect of supplementing BD with NSP enzymes, prebiotics alone or in combination of these additives was observed on intestinal $\mathrm{pH}$. Supplementation of NSP enzymes alone $(4.25 \mathrm{cP})$ or in combination with prebiotics $(4.37 \mathrm{cP})$ reduced $(\mathrm{P}<0.001)$ the intestinal viscosity. Significant $(\mathrm{P}<0.001)$ difference on E. coli count $(\log 10)$ was observed among the birds fed SD, BD, BD supplemented with NSP enzymes, prebiotics alone or in combination (TABLE 6).

\subsection{Cost of feeding}

Supplementation of NSP enzymes or prebiotics or both did not increase the cost of feed in comparison to SD. Supplementation of NSP enzymes, prebiotics alone or in combination to BD did not increase the cost of feeding during finisher phase and total period.The cost of production per kg live weight gain is given in TABLE 5. Supplementation of BD with NSP enzymes or prebiotics or in combination significantly $(\mathrm{P}<0.01)$ reduced cost of production per kg live weight gain.

\subsection{Body weight gain}

\section{Discussion}

Supplementation of NSP enzymes and prebiotics to low calorie diet (BD) did not affect body weight gains during the 1-42 day experimental period. The results obtained in the present study are in agreement with [14];[15]and[16] who reported no effect of MOS supplementation on performance of broilers. The magnitude of the associative effect of NSP enzymes and MOS in starter, finisher and the overall total weight gain was $5.78,8.28,7.50 \%$ and $2.5,2.64,3.29 \%$ higher than the basal diet and standard diet, respectively. 4.2Feed intake

Supplementation of BD with NSP enzymes and prebiotics alone or in combination had no effect on finisher and total feed intake and was lower than that of SD.[16] and [15] reported no effect on feed intake with supplementation of inulin or FOS and MOS. Contrary to the results obtained in the present study, [17] observed $2.2 \%$ more feed intake in low energy corn soy diets $(0.46 \mathrm{MJ} / \mathrm{kg}$ diet $)$ compared to standard control diet but statistically insignificant.

\subsection{Feed conversion ratio}

Comparatively higher weight gains, with lower feed intake in broilers fed BD supplemented with NSP enzymes, prebiotics alone or combination resulted in significantly higher feed: gain ratio compared to un supplemented basal diet and standard diet. Similar results were reported by [14] who observed a $2 \%$ decrease $(\mathrm{P}<0.05)$ in FCR when the corn, soy wheat diets supplemented with isomalto oligosaccharides. [18]observed higher feed: gain ratio in females but not in male broiler chicken due to supplementation of inulin or FOS at 10 $\mathrm{g} / \mathrm{kg}$ diet. [19]compared the dose effect of isomalto- oligosaccharides (IMO) at 0.3, 0.6, 0.9 and $1.2 \%$ and found lower feed conversion ratio than control in broilers. Contrarily [16] found no significant effect on feed conversion ratio with supplementing combination of inulin and enzyme complex to broiler diets. [14]Also found, (BIO-MOS) supplementation at 1 and $2 \mathrm{~g} / \mathrm{kg}$ in sorghum wheat based diet had no effect on feed conversion efficiency.

\subsection{Nutrient retention}

The retention of $\mathrm{OM}, \mathrm{CP}$ and GE was lower in BD compared to SD and supplementing NSP enzymes to $\mathrm{BD}$ improved $(\mathrm{P}<0.05)$ retention of these nutrients and were comparable to SD. But no further improvement was observed with supplementation of NSP enzymes with prebiotics. Associative effect of NSP enzymes and prebiotics was observed for CP retention. Supplementation of BD with NSP enzymes and prebiotics had no effect on the retention of DM, CF, EE, NFE and phosphorus. Per cent tibia ash improved with NSP enzymes or prebiotics supplementation to BD. The results are in line with [14] who reported no significant difference in apparent digestibility of starch among MOS treatments and the negative control. However, the improved retentions of other proximate principles viz, OM, CP and GE are in line with results of [20] who reported increased digestibility of DM, CP, CF and EE in enzyme supplemented groups. 


\subsection{Carcass characteristics}

The slaughter attributes, except for breast yield were not affected by supplementation of NSP enzymes and prebiotics to BD. Breast yield with supplementation of either NSP enzymes or prebiotics alone to $\mathrm{BD}$ was not influenced but adding both these feed additives significantly $(\mathrm{P}<0.01)$ increased the breast yield. The present findings on slaughter attributes were in agreement with [21] who observed no effect of enzyme supplementation on carcass yield, carcass composition and giblet yields. Several other workers [22] and [23] reported no significant effect of enzyme supplementation to corn soybean meal diets in broilers on carcass characteristics.

\subsection{Gut conditions}

Intestinal $\mathrm{pH}$ was not influenced by supplementation of NSP enzymes and/or prebiotics in the present study but addition of prebiotics alone or in combination with NSP enzymes significantly reduced $E$. coli count and was comparable to SD. These results are in line with [14] who reported, no effect of MOS on intestinal $\mathrm{pH}$ and significantly $(\mathrm{P}<0.05)$ reduced bacteria i.e. Lactobacilli, coli forms, enterococi count in ileum and caecum. [24] also observed significant reduction in the total aerobes and coli forms with addition of sucrose thermal oligosaccharides at 3.7 and $7.5 \%$ level but had little effect on either aerobically or anaerobically enumerated Lactoballi or in Bifidobacterial numbers in the caecum. Similar results are found by [16] on supplementation of inulin and enzyme complex containing xylanase and glucanase on Bifidobacteria and Lactobacilli counts determined in ileal and caecaldigesta and $\mathrm{pH}$ values. Contrary to the above finding [19] observed no effect of supplementation of isomalto oligosaccharide on viable counts of aerobes, Lactobacilli or E. coli. Intestinal viscosity was reduced in BD supplemented with prebiotics and reduction was still higher with NSP enzymes supplementation. Feed additives may have positively affected the viscosity in the intestine due to their positive effect on the intestinal microflora.

\subsection{Cost of feeding}

. Supplementing NSP enzymes and prebiotics or both of these to BD did not increase the cost of feeding. The feed cost per kg live weight gain was significantly $(\mathrm{P}<0.01)$ reduced by Rs.3.21/kg and Rs. $4.40 / \mathrm{kg}$ in supplemented groups compared to un supplemented BD and SD respectively. The results shows that cost of production of broiler can be considerably brought down by supplementing feed additives to low calorie diets resulting in higher FCR and nutrient retention. Similar results were reported by [25] where enzyme supplementation of $0.5 \mathrm{~g} / \mathrm{kg}$ diet of standard and low nutrient density diets (5\% less energy and protein) reduced cost of production per $\mathrm{kg}$ gain by $7.5 \%$ and $1 \%$ respectively. Several previous studies [26]; [27] have reported that feed cost was reduced by enzyme supplementation.

\section{Conclusion}

Supplementation of NSP enzymes along with prebiotics to BD (-225 kcal lower ME than SD) significantly $(\mathrm{P}<0.05)$ improved the feed conversion ratio, digestibility of most of the nutrients and reduced $(\mathrm{P}<0.05)$ intestinal $\mathrm{pH}$, viscosity and $E$. coli count in broilers. There was no effect on slaughter characteristics with reduction in energy and supplementation of NSP enzymes and prebiotics. The feed cost per kg LWG significantly $(\mathrm{P}<0.05)$ reduced with supplementation of NSP enzymes with prebiotics.

\section{References}

[1] M.Choct, Feed polysaccharides: Nutritional roles and effect of enzymes. 2011IV CLANA CBNA/AMENA, Sao Pedro, S P, Brazil, Engormix. com.

[2] V.Malathi, and G.Devegowda,In vitro evaluation of non starch polysaccharide digestibility of feed ingredients by enzymes, Poultry Science, 80,2001, 302-305.

[3] R.M.Saunders, Rice bran: composition and potential food uses, Food Reviews Science Journal,1986, 62: 5-6.

[4] C. H.M.Smits, and G.Annison,Non starch plant polysaccharides in broiler nutrition towards a physiologically valid approach to their determination, World Poultry Science Journal,52,1996, 203-221.

[5] H.Terada, J.Hara, N.Sakamoto, S.Sato, Takagi, and T.Mitsuok,Effects of dietary supplementation with Lactosucrose (4G- $\beta$-DGalactosylsucrose) on cecal flora, cecal metabolites, and performance in broiler chickens, Poultry Science,73, 1994, 1663-1672.

[6] A. L.Hughes, J.P.Dahiya, C. L.Wyatt, and H.L.Classen, Effects of phytase supplementation on the performance, egg quality and phosphorus excretion of laying hens fed different levels of dietary calcium and non phytatephosphorus, Poultry Science, 88, 2009, 1191-1198.

[7] AwadWageha, KhaledGhareeb and Josef Bohm, Intestinal structure and function of broiler chickens on diets supplemented with a symbiotic containing Enterococcus faecium and oligosaccharides, International Journal of Molecular Science, 9 (11),2008,22052216.

[8] M.Falaki, M.ShamsShargh,B.Dastar,andS.Zerehdaran,Effects of different levels ofprobiotic and prebiotic on performance and carcass characteristics of broiler chickens,Journal of Animal and Veterinary Advances, 10(3,)2011, 378 - 384.

[9] National Research Council,Nutrient Requirements of Poultry, 9th ed. National Academy Press, Washington, DC, 1994.

[10] AOAC,Official Methods of Analysis of Association of official Analytical chemists, 2005 , Association of official Analytical chemists).

[11] E.C.Clayden,Practical section cutting and staining, 4th Edition, J and Churchil limited, 1962, 
[12] C. F.A.Culling,Hand Book of Histopathological Techniques, London Butterworth and company. (publisher,1957) Ltd.

[13] D. D. Duncan, Multiple range and multiple ' F' test, Biometrics, 1955, 11:1-42.

[14] Y.Yang, P.A.Iji, A.Kocher, E.Thomson, L.L.Mikkelsen, and M.Choct, Effects of mannanoligosaccharide in broiler chicken diets on growth performance energy utilization, nutrient digestibility and intestinal microflora,British Poultry Science, 492008, 186-194.

[15] B.Baurhoo, A.Letellier, X.Zhao, and C.A.RuizFeria,Cecal populations of lactobacilli and bifidobacteria and Escherichia coli populations after in vivo Escherichia coli challenge in birds fed diets with purified lignin or mannanoligosaccharides, Poultry Science, 86, 2007, 2509-2516.

[16] A.Rebole, L. T.Ortiz, M.L.Rodriguez, C.Alzueta, J.Trevino, and S. Velasco,Effects of inulin and enzyme complex, individually or in combination, on growth performance, intestinal mocroflora, cecal fermentation characteristics and jejuna histomorphology in broiler chickens fed in wheat and barley based diet,Poultry Science,89, 2010, 276-286.

[17] A.J.Cowieson, M.R.Bedford, and V.Ravindran, Interactions between xylanase and glucanase in maize-soy-based diets for broilers,British Poultry Science 51 (2),2010, 246-257.

[18] Yusrizal, and T. C.Chen, Effect of adding chicory fructans in feed on broiler growth performance serum cholesterol and intestinal length,International Journal of Poultry Science 2(3),2003, 214-219.

[19] W. F.Zhang, D. F.Li, W. Q.Lu, and G.F.Yi, Effects of Isomalto-oligosaccharides on broiler performance and intestinal microflora, Poultry Science 82,2003, 657-663.

[20] R.S.Bhatt, Manoj Sharma, and B.S.Katoch, Effect of supplementation of diet with fibre degrading enzyme on performance and nutrient utilization in broilers, Indian Journal of Animal Nutrition 8 (2),1991, 135-138.

[21] R.S.Berwal, O.P.Lohan, and S.ShiagZile, Effect of dietary crude fibre levels and enzyme supplementation on performance and carcass characteristics of broiler chicks, Indian Journal of Poultry Science 43, 2008, 2.

[22] P.V.NarsimhaRao,Effect of enzymes in feed on broiler performance, M V Sc. Thesis ANGR Agricultural University, Hyderabad, 1998.

[23] M.HanumanthaRao, V.Ravinder Reddy, and V.Ramasubba Reddy, Effect of commercial enzymes on the performance of broiler, Indian Journal of Poultry Science 38(3),2003, 291-293.

[24] J.I.Orban, J. A.Patterson, A. L.Sutton, and G. N.Richards, Effect of sucrose thermal oligosaccharide caramel, dietary vitaminmineral level, and brooding temperature on growth and intestinal bacterial populations of broiler chickens, Poultry Science 76, 1997, $482-490$.

[25] J.Ramesh, and D.Chandrasekaran, Effect of exogenous enzyme supplementation on performance of cockerels, Tamil Nadu Journal Veterinary and Animal Sciences 7 (1),2011, 29-34.

[26] M.Augelovicova, and I.Michalik, A test of enzymatic preparation in relation to performance and commercial utilization of feeds in broiler chickens,Zivocisna-Vyroba. 42 (4): 1997, 175-180.

[27] M.Morkanas, G.Kbtitskas, and V.Kublitsken, An enzyme premix,Poultry Abstract 19 (1-4),1993, 43-109. 